\title{
The Effect of Massage on Weight Gain of Low-Weight Hospitalized Infants: A Randomized Clinical Trial
}

\author{
Sahar Johari' ${ }^{1}$ Hojjat Allah Haghgou' ${ }^{\text {, Mostafa Daemi }}{ }^{2}$, Tahereh Rezaeiyan ${ }^{3}$, Zahra Mosala Nejad $^{3 *}$ \\ 1. Department of Occupational Therapy, University of Social Welfare and Rehabilitation Sciences, Tehran, Iran. \\ 2. Department of Speech Therapy, University of Social Welfare and Rehabilitation Sciences, Tehran, Iran. \\ 3. Department of Physical Therapy, University of Social Welfare and Rehabilitation Sciences, Tehran, Iran.
}

Citation: Johari S, Haghgou HA, Daemi M, Rezaeiyan T, Mosala Nejad Z. The Effect of Massage on Weight Gain of Low-Weight Hospitalized Infants: A Randomized Clinical Trial. Physical Treatments. 2016; 5(4):205-210.

do

Article info:

Received: 12 Jul. 2015

Accepted: 08 Nov. 2015
Keywords:

Massage, Low birth weight neonate, Weight gain, Tactile-kinetic stimulation

\begin{abstract}
A B S T RA C T
Purpose: Low birth weight (LBW) is one of the most serious health problems in infants. Many studies indicate that LBW infants, who survive, may suffer from long- and short-term physical, mental, and social problems. This study aimed to determine the effect of massage therapy on weight gain of LBW neonates.

Methods: This study was a randomized clinical trial. A total of 45 LBW neonates were randomly allocated into experiment and control group. Three 15-minute period massages per day were administered in 5 days for the experiment group. Infants' weights were measured in both groups in 5 all days.

Results: Based on the results, weight gain in the experiment group was significantly higher than the control group.

Conclusion: Massage through tactile-kinetic stimulation result in weight gain of LBW neonates. Massage therapy can be recommended as the special and complementary care for LBW neonates. It can also be effective in prevention of neurologic and developmental problems in infants.
\end{abstract}

\section{Introduction}

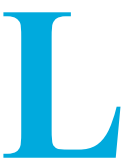

ow birth weight (LBW) is one of the most serious health problems in today's world. Although LBW neonates comprise $6 \%$ to $7 \%$ of the total births, $75 \%$ of the death rate in neonates is implicated on it. Every year, 19\% of neonates in the world are born with LBW which is the major cause of the infants' mortalities and morbidities. The premature birth rate and LBW in Iran is not exactly clear, but some sources in Iran have estimated the rate of LBW as 12\% [3]. LBW babies (who survive) suffer 2 or 3 times more than normal children of disabilities and health problems as well as long-term and short-term psychological and social problems [4]. The growth and development of premature infants are of particular importance and weight is the most important factor in this regard [5].

Since infants actually receive very little nutrients in their first 3 to 4 days of lives (until the flow of the breast

* Corresponding Author:

Zahra Mosala Nejad, PhD

Address: Department of Physical Therapy, University of Social Welfare and Rehabilitation Sciences, Kodakyar Ave., Daneshjo Blvd., Evin, Tehran, Iran. Phone: +98 (935) 3977654

E-mail: zmosallanezhad@yahoo.com 
milk or other feeding methods be established), a progressive reduction in their body weights occurs. The premature infants lose more weight and regain the normal birth weight at a lower speed compared to the normal weight ones [6]. Gestational age and consequently the neonates' weight can affect the future weight gain in them, i.e. the lower the birth weight, the more weight loss in infants than the normal ones during the first 2 weeks of life [7]. Also, the lower the birth weight, the more the risk of the neurological complications and mental retardation in newborn babies. As much as $50 \%$ of the neonates with the birth weight of 500-750 g are at high risk of developing severe nervous system disabilities such as blindness, deafness, mental retardation, and cerebral palsy. The overall rate of neurodevelopmental disorders such as cerebral palsy, visual and audio impairments and learning disabilities in babies with LBW varies from $10 \%$ to $20 \%$ [8]. In addition to the effects on the infants' health, LBW can affect the family's mental state so that these parents experience a high level of anxiety about their children's long-term complications and their failure in reaching a normal growth and development [9].

One of the major problems in premature infants and their hospitalizations is their low weights. In many cases, insufficient weight gain is the main and important reason in prolongation of the infants' hospitalization, its high costs, and related problems [10]. Given that with the weight gain, the risk of anomalies in low weight neonates decreases, the effectiveness of various therapeutic methods to gain weight in LBW neonates is of significant importance. Massage or tactile-kinetic stimulation is one of the developmental interventions. Massaging with or without using oil is one of the ways in the premature neonates' weight gain [10]. It not only contributes to the infants' growth and development, but also have many benefits for the infant and his or her parents which leads to high regards in researchers to pay attention to [11]. New studies suggest that child' massage after birth and during the first months of life contributes to the child's growth and development [12] as well as the improvement of the weight gain and sleep patterns in these infants $[13,14]$. It can also lead to the better mineralization of bones, early discharge from the hospital and more efficient kinetic-behavioral responses $[15,16]$.

Several studies have been conducted on the effects of the massage therapy on the growth and the development of the various physical and even the behavioral aspects of infants. However, most of these studies had been conducted when the medical intervention and therapy needed for the infants were finished and they were discharged from ICU to the other care units. On the other hand, there is still no consen- sus on how to administer the massage and its processes, so we need more accurate and detailed studies in this area. Therefore, considering the high rate of LBW babies, the risk of the developmental delays and problems in these infants, and the golden time limit for the help and the welltimed treatment, this study aimed to examine the effects of massage and tactile-kinetic stimulation on the infants' weight gain in neonatal intensive care units (NICUs).

\section{Materials and Methods}

The present study was a double-blind clinical trial (Clinical Trail Code: IRCT201411189014N47). The sample size was determined based on the previous studies and relevant formulas with $95 \%$ power to assess the effect of the massage. In this regard, each group should possess at least 16 participants [17]. However, in this study, to prevent the effect of participants' dropout, a total of 45 hospitalized premature infants in Hamadan Fatemieh Hospital were recruited. The sampling was conducted consecutively from spring to summer 2015 by purposeful method and the participants, after being qualified for the study, were randomly assigned into experiment $(n=23)$ and control groups $(n=22)$. The study inclusion criteria were as follows:

- Birth weight less than 2400 g;

- Gestational age between 25 to 34 weeks;

- Stable medical conditions based on the pediatrician's diagnosis;

- Oral intake start;

- Being a 5-day neonate at the beginning of the study.

Also, the exclusion criteria were as follows:

- Having genetic disorders, congenital heart problems, central nervous system, and intraventricular hemorrhage;

- A history of drug abuse in mothers;

- Positive HIV test in children;

- Children's need for surgery;

- The beginning of breast feeding.

After informing the parents of the purpose, process, and potential benefits of the treatment used, as well as its safety for the infants and assuring them of the confidentiality of their information in the research, the consent 
forms were distributed among the parents and the infants' medical and demographic data were entered in a medical questionnaire using the mother and infant's medical records. All infants were weighed by a person other than the therapist and then, the experiment group received the treatment by Tiffany method [17] 3 times a day for 5 days, each time for 15 minutes of tactile stimulation in accordance with the following schedule which included 3 phases. Each 15-minute period included three 5 minute phases that in the first and last phases, the infant was lying on the stomach and was touched very gently with the soft parts of fingers of both hands. In these two phases, each of the following areas was consecutively touched for 1 minute:

First phase: mobile touching of the following areas in the prone positions:

- From the top of the head to the neck;

- From the neck to the shoulders;

- From the top of the back to waist;

- From the hips and then in the backward direction on both feet;

- From shoulders to the hands and then to return to the areas listed in both hands, 12 movements each one 5 seconds.

Second phase (middle phase): the infant was lying on his back and with the smooth and passive range of motions, the flexion and extension order were given to these 5 areas:

Right arm, left arm, right leg, left leg, both legs together in 5 one-minute steps that each step included 6 ten-second movements.

Third phase (the last phase) was the same as the first phase.

Five days later, the same experimenter who was blind to sampling the infants measured the infants' weights with the same first-used scale. This study was approved by the Ethics Committee of the University of Medical Sciences and the researchers tried their best to maintain all the ethical principles in all phases of the study. After data collection and reviewing their normal distribution, parametric tests, including independent $t$ test and dependent $t$ test, Chi-square, and ANCOVA were performed. In ANCOVA test, the first day variable was considered as covariate and the ANCOVA test was used for compar- ing the values between the two groups after the treatment considering the first-day weight added the covariate. For their analysis, SPSS version 16 was used.

\section{Results}

At the first of the study, the two groups were homogenous in terms of qualitative treatment variables including gender, recovery, oxygen therapy, receiving phototherapy, fluid therapy, and antibiotics and also, in terms of a-bit-treatment variables, including head circumference, height and weight at birth, duration of the pregnancy, 1-minute and 5-minute Apgar and the weight before treatment $(\mathrm{P}>0.05)$ (Tables 1\&2).

Finally, to compare the two groups regarding the effects of the treatment on infants' weight gain with respect to the normal distribution of data, variance homogeneity, the distance between the measurements, insignificant correlation between the covariate variables (first-day weight) and the independent variable $(\mathrm{P}>0.05)$, the analysis of covariance was used. Its results showed that the weight gain in the experiment group has a significant difference from the control group ( $\mathrm{P}=0.003)$. Table 3 includes these statistical tests.

\section{Discussion}

This study aimed to analyze the effects of massage on the weight gain of hospitalized low-weight infants in NICUs of Hamedan City hospitals. According to the results of this study, it was recognized that massage therapy increases the weight in LBW infants. The results of this study agree to Khoshrouzeh et al. results, which investigated the effects of massage by mothers on LBW infants' physical growth (48 infants in two groups). They showed that massage therapy affected the LBW infants' physical growth and increased their weight and height [1].

Of course, one of the differences which can be cited between Khoshrouzeh study and this study is the administration of massaging by mothers. Badie et al. examined the effects of massage by mothers and nurses on the weight gain of 28 - to 34 -week premature infants. The results of this study supported the effects of the massage therapy on LBW infants' weight gain [18]. However, Badie et al. included the infants in their study after their entering to the post NICU. Also, in another study by Golchin et al. the effects of deep massage therapy on weight gain of LBW infants were studied in two groups $(n=20)$ of LBW infants. The results of this study showed that deep massage therapy increased the LBW infants' weight [19]. Likewise, in Scafidi study, 93 premature 
Table 1. Comparison between the control and experiment groups with regard to nominal variables before the intervention.

\begin{tabular}{|c|c|c|c|c|c|c|c|c|}
\hline \multirow{2}{*}{ Variable } & & \multicolumn{2}{|c|}{ Experiment Group } & \multicolumn{2}{|c|}{ Control Group } & \multicolumn{3}{|c|}{ Chi-Square Test/Fisher's Exact Test } \\
\hline & & No. & $\%$ & No. & $\%$ & Statistics & df & Probability \\
\hline \multirow{3}{*}{ Gender } & Male & 11 & 47.8 & 14 & 60.9 & \multirow{3}{*}{0.203} & \multirow{3}{*}{1} & \multirow{3}{*}{0.674} \\
\hline & & & & & & & & \\
\hline & Female & 12 & 52.2 & 9 & 39.1 & & & \\
\hline \multirow{3}{*}{ Delivery type } & Normal delivery & 3 & 13.0 & 6 & 27.3 & \multirow{3}{*}{-} & \multirow{3}{*}{-} & \multirow{3}{*}{0.284} \\
\hline & & & & & & & & \\
\hline & Cesarean & 20 & 87.0 & 16 & 72.7 & & & \\
\hline \multirow{3}{*}{ Recovery } & Received & 16 & 80.0 & 20 & 87.0 & \multirow{3}{*}{-} & \multirow{3}{*}{-} & \multirow{3}{*}{0.816} \\
\hline & & & & & & & & \\
\hline & Not received & 4 & 20.0 & 3 & 13 & & & \\
\hline \multirow{3}{*}{ Oxygen } & Received & 19 & 82.6 & 19 & 86.4 & \multirow{3}{*}{-} & \multirow{3}{*}{-} & \multirow{3}{*}{0.999} \\
\hline & & & & & & & & \\
\hline & Not received & 4 & 17.4 & 3 & 13.6 & & & \\
\hline \multirow{3}{*}{ Phototherapy } & Received & 15 & 65.2 & 14 & 60.9 & \multirow{3}{*}{0.180} & \multirow{3}{*}{1} & \multirow{3}{*}{0.909} \\
\hline & & & & & & & & \\
\hline & Not received & 8 & 34.8 & 9 & 39.1 & & & \\
\hline \multirow{3}{*}{ Fluid therapy } & Received & 14 & 60.9 & 10 & 43.5 & \multirow{3}{*}{0.711} & \multirow{3}{*}{1} & \multirow{3}{*}{0.399} \\
\hline & & & & & & & & \\
\hline & Not received & 9 & 39.1 & 13 & 56.5 & & & \\
\hline \multirow{3}{*}{ Antibiotics } & Received & 11 & 47.8 & 12 & 52.2 & \multirow{3}{*}{1.13} & \multirow{3}{*}{1} & \multirow{3}{*}{0.548} \\
\hline & & & & & & & & \\
\hline & Not received & 12 & 52.2 & 11 & 47.8 & & & \\
\hline
\end{tabular}

PHYSICAL TREA TMENTS

* Those variables that their statistics and the degree of freedom are not reported have been analyzed with the Exact Fischer test because the frequency in more than $20 \%$ of the expected cells was less than 5.

Table 2. Comparison between the control and experimental groups with regard to quantitative variables at the beginning of the study.

\begin{tabular}{|c|c|c|c|c|c|c|c|c|c|}
\hline \multirow{2}{*}{ Variable } & \multicolumn{3}{|c|}{ Experiment Group } & \multicolumn{3}{|c|}{ Control Group } & \multicolumn{3}{|c|}{ Independent T Test } \\
\hline & No. & Mean & SD & No. & Mean & SD & Statistics & df & Probability \\
\hline Birth weight (g) & 23 & 1545.60 & 417.47 & 22 & 1737.50 & 39.745 & -1.54 & 43 & 0.131 \\
\hline Pregnancy (wk) & 23 & 31.95 & 2.38 & 20 & 32.20 & 1.70 & -0.380 & 41 & 0.706 \\
\hline Height at the beginning of the study $(\mathrm{cm})$ & 19 & 40.89 & 4.66 & 19 & 42.42 & 4.71 & -1.01 & 36 & 0.323 \\
\hline Head circumference $(\mathrm{cm})$ & 19 & 29.55 & 1.89 & 19 & 30.31 & 2.23 & -1.13 & 36 & 0.264 \\
\hline Apgar at $1^{\text {st }}$ minute & 20 & 5.85 & 1.66 & 22 & 5.86 & 1.58 & -0.027 & 40 & 0.978 \\
\hline Apgar at $5^{\text {th }}$ minute & 18 & 7.77 & 1.66 & 22 & 7.45 & 1.29 & 0.690 & 38 & 0.494 \\
\hline
\end{tabular}

PHYSICAL TREA TMENTS

Table 3. The analysis of weight variable of the infants after treatment.

\begin{tabular}{|c|c|c|c|c|c|}
\hline \multirow{2}{*}{ Variable } & Experiment & Control & \multirow{2}{*}{ df } & ${ }^{*} \mathbf{t}$ & \multirow{2}{*}{ Probability } \\
\hline & (SD)Mean & (SD)Mean & & ${ }^{* *} \mathbf{f}$ & \\
\hline Weight before treatment (g) & $1448.47(403.05)$ & 1664.77(399.49) & 43 & -1.89 & 0.065 \\
\hline Weight after treatment (g) & $1520.65(376.85)$ & $1600.22(336.2)$ & 2 & 6.50 & 0.003 \\
\hline
\end{tabular}

*t for independent $t$ test.

PHYSICAL TREA T MENTS

${ }^{* *}$ f for ANCOVA test. 
neonates with average gestational age of 30 weeks were randomly divided into massage therapy and control groups. After receiving massage, the obtained results showed that there was a gain weight in massage therapy group compared to the control group [20]. The difference of the present study with the Scafidi study was that many infants entered in this study had a gestational pregnancy age of 28 weeks.

Based on the results of this study and other studies, the physiological effects of massage on the body can be inferred. Massage can release endorphins, which cause relaxation, reduce muscle tensions, and help the disposal of waste materials. Regular rhythmic tactile stimulations reduces stress and secretion of cortisol as well as controlling temperature and infections in neonates [8]. Massage also improves blood circulation, strengthens the immune system through circulating the lymph fluid throughout the body and disposing the harmful substances. In addition, massage therapy strengthens the preterm infants against stress through its effects on hypothalamicpituitary-adrenal axis $[15,21]$. It can also be noted that massage therapy can, with the increase in the activity of vagus nerve, release the effective hormones involved in food intake, increase the gastric motility, and increase the insulin level, insulin-like growth factor, and oxytocin [4].

On the other hand, massage helps the infant's growth by increasing the levels of epinephrine and norepinephrine which cause an increase in catecholamine [4]. However, there are some research in this area such as Li et al. (2006) with opposite results. In this study, fifty-two 2- to 6-month-old healthy infants with no premature backgrounds were randomly assigned into two groups $(n=26)$ and received massage. Unlike the previous studies, the results of this study did now show any significant difference in improving the physical growth and weight gain [22]. To explain the discrepancy in results, it can be mentioned that in Li study, the healthy infants with no prematurity and LBW were studied. However, in this study and other similar studies, low weight and infants' prematurity were the essential criteria to enter to the study. In addition, in most similar studies, infant's age was very low so that the research was conducted on them before their leaving the hospital while in Li study all studied infants were reported to be 2 to 6 months old. Another study was done by Asgari et al. In this study which aimed to investigate the effects of tactile-kinetic stimulation on weight gain of LBW infants, 40 qualified infants were randomly chosen and divided into two groups of experiment and control. The experiment group received the tactile-kinetic stimulation for 10 days immediately after birth, 3 times a day, and each time for
15 minute. The stimulation started with the moderate occipital pressure and finally ended with legs.

The results of this study showed that the tactile-kinetic stimulation did not have any effect in weight gain of infants, which was not consistent with the results of the present study [23]. In Asgari research, also, low weight infants received tactile-kinetic stimulation immediately after birth. Whereas in the first days of life, infants naturally lose weight [23]; therefore, the tactile-kinetic stimulations must be applied at least 5 days after birth as it was applied in this study. Among the limitations of this study, we can refer to the early infants' discharge from the hospital because of the shortages in the number of the NICU beds. Our study results indicate that massage therapy affects weight gain of the LBW infants.

\section{Acknowledgements}

All the cooperation from the pediatricians and the staff and supervisors in the NICUs in Hamedan hospitals and the infants' families are highly appreciated.

\section{Conflict of Interest}

The authors declared no conflict of interests.

\section{References}

[1] Hoseinzadeh Kh, Azima S, Keshavarz T, KaramizadeT, Zaree N. [The effect of Massage on physical growth of low birth weight infants in maternity wards (Persian)]. Journal of Isfahan Medical School. 2012; 29(165):2175-169.

[2] Hadi N. [Maternal and child health (Persian)]. Shiraz: Shiraz University of Medical Sciences Publication; 2006.

[3] Naseri M. [Care of very low birth weight neonate (Persian)]. Tehran: Scientific society of fertility \& infertility scientists. 2005.

[4] Javadifar N, Faal Siahkal Sh, Tadayon M, Dehdashtian M, Latifi SM. [The effect of massage with coconut oil on weight gain in preterm neonate (Persian)]. Jundishapur Scientific Medical Journal. 2009; 8(2):247-54.

[5] Behrman RE, Kliegman RM, Jenson HB. Nelson textbook of pediatrics. $17^{\text {th }}$ ed. Philadelphia: Sanders Company; 2003.

[6] Cunningham FG, Leveno KJ, Bloom SL, Hauth J, Gilstrap L, Wenstrom K. Williams obstetrics. 22 ${ }^{\text {nd }}$ ed. New York: McGraw-Hill Companies, Inc; 2005.

[7] Fernandez A, Patkar S, Chawla C, Taskar T, Prabhu SV. Oil application in preterm babies. A source of warmth and nutrition. Indian Pediatrics. 1987; 24(12):1111-116. 
[8] Roozbehani N, Narenji F. [The effect of massage with Sesame oil on infant anthropometric measurements and their sleep pattern (Persian)]. Journal of Shahrekord University of Medical Sciences. 2009; 11(3):34-39.

[9] Arifeen SE, Black RE, Caulfield LE, Antelman G, Baqui AH, Nahar Q, et al. Infant growth patterns in the slums of Dhaka in relation to birth weight, intrauterine growth retardation, and prematurity. American Journal of Clinical Nutrition. 2000; 72(4):1010-017. PMID:11010945

[10] Saeidi R, Partovi S, Kianifar HR, Gholami Robatsangi M, Ghorbani M. [Evaluation of massage with oil containing medium chain triglyceride on weight gaining in preterm (Persian)]. Journal of Semnan University of Medical Sciences (Koomesh). 2009; 11(1):1-6.

[11] Sankaranarayanan K, Mondkar JA, Chauhan MM, Mascarenhas BM, Mainkar AR, Salvi RY. Oil massage in neonates: an open randomized controlled study of coconut versus mineral oil. Indian Pediatrics. 2005; 42(9):877. PMID:16208048

[12] Vickers A, Ohlsson A, Lacy JB, Horsley A. Massage for promoting growth and development of preterm and/or low birth-weight infants. Cochrane Database of Systematic Reviews. 2000; 2:CD000390. doi: 10.1002/14651858.CD000390. pub2

[13] Agarwal KN, Gupta A, Pushkarna R, Bhargava SK, Faridi MM, Prabhu MK. Effects of massage \& use of oil on growth, blood flow \& sleep pattern in infants. Indian Journal of Medical Research. 2000; 112:212-17. PMID: 11247199

[14] Ferber SG, Kuint J, Weller A, Feldman R, Dollberg S, Arbel E, Kohelet D. Massage therapy by mothers and trained professionals enhances weight gain in preterm infants. Early Human Development. 2002; 67(1-2):37-45. PMID: 11893434

[15] Acolet D, Modi N, Giannakoulopoulos X, Bond C, Weg W, Clow A, Glover V. Changes in plasma cortisol and catecholamine concentrations in response to massage in preterm infants. Archives of Disease in Childhood. 1993; 68(1):29-31. doi: 10.1136/adc.68.1_spec_no.29

[16] Hack M, Flannery DJ, Schluchter M, Cartar L, Borawski E, Klein N. Outcomes in young adulthood for very-low-birthweight infants. New England Journal of Medicine. 2002; 346(3):149-57. doi: 10.1056/nejmoa010856

[17] Field TM, Schanberg SM, Scafidi F, Bauer CR, Vega-Lahr N, Garcia R, et al. Tactile/kinesthetic stimulation effects on preterm neonates. Pediatrics. 1986; 77(5):654-58. PMID: 3754633

[18] Badiee Z, Sasamshariati S, Pourmorshed P. [Massage therapy by mother or nurse: effect on weight gain in premature infants (Persian)]. Journal of Isfahan Medical School. 2011; 29(114):804-11.

[19] Golchin M, Rafati P, Taheri P, Nahavandinjad S. [Effect of deep massage on increasing body weight in low birth weight infants (Persian)]. Journal of Kashan University of Medical Sciences. 2010; 14(1):46-50.

[20] Scafidi FA, Field TM, Wheeden A, Schanberg S, Kuhn C, Symanski R, et al. Cocaine-exposed preterm neonates show behavioral and hormonal differences. Pediatrics. 1996; 97(6):851-85. PMID: 8657526

[21] Hernandez-Reif M, Diego M, Field T. Preterm infants show reduced stress behaviors and activity after 5 days of massage therapy. Infant Behavior and Development. 2007; 30(4):557 61. doi: 10.1016/j.infbeh.2007.04.002

[22] Lee HK. The effect of infant massage on weight gain, physiological and behavioral responses in premature infants. Journal of Korean Academy of Nursing. 2005; 35(8):1451460. PMID:16415626

[23] Aliabadi F, Askari R, Taghizadeh G. [Effect of tactile-kinesthetic stimulation on weight gaining of low birth weight neonates (Persian)]. Journal of Modern Rehabilitation. 2010; $4(3-4): 29-34$. 